\title{
EL RETABLO DE TEOPISCA EN CHIAPAS
}

\author{
P O R
}

\section{F R A N S B L O M}

L A literatura sobre el arte colonial del Estado de Chiapas es sumamentodavía se conservan en el Estado es más limitado todavía. Salvador Toscano, Heinrich Berlin, Jorge Olvera, George Kubler y Elizabeth Wilder tratan esta materia en sendos artículos y libros. ${ }^{1}$ Mariano Trujillo Robles ha escrito algunos artículos en diferentes revistas populares con el fin de atraer el interés de los turistas, pero una obra completa no se ha escrito. Mi fino amigo, Jorge Olvera, está reuniendo datos para la Historia del Arte Colonial en Chiapas y, con su conocida energía, ha recorrido el Estado para investigar y buscar todo lo interesante. Ojalá que pronto encuentre apoyo para que se publique su obra.

1 Toscano, Salvador. "Chiapas, su historia y su arte colonial", Anales del Instituto de Investigaciones Estéticas. Núm. 8, 1942.

Berlin, Heinrich. "El convento de Tecpatán". Amales del Instituto de Invesligaciones Estéticas. Núm. 9, 1942.

Kubler, George. "Mexican architecture in the sixteenth century". 2 tomos, 1951.

Olvera, Jorge. "Copanaguastla, joya del Plateresco en Chiapas". Ateneo de Chiapas. Núm. 2.

Wilder, Elizabeth. "Mexico in sculpture 1521-1821". 1950.

- Trujillo R. Mariano. "San Cristóbal las Casas, sus atractivos turísticos". Revista Gráfica. Chiapas. Tomo IV, núm. 29.

Las fuentes arriba mencionadas se pueden consultar en la Biblioteca Fray Bartolomé, San Cristóbal Las Casas, Chiapas. 
Las fuentes antiguas históricas son pocas. La mejor es el Diario de fray Tomás de la Torre, publicado en la gran obra de fray Francisco Ximénez, ${ }^{2}$ así como en algunos datos que se encuentran en el libro, ahora rarísimo, del obispo Orozco y Jiménez. ${ }^{3}$ Revoluciones y otros estragos han destruído mucho los archivos eclesiásticos y seculares del Estado.

Teopisca está situado sobre la carretera panamericana (llamada de Cristóbal Colón, el gran navegante, que casi nunca anduvo por tierra) y tiene alrededor de 5000 habitantes. Es un pueblo de agricultores; lugar de tierras fértiles, bonito $y$ aparentemente tranquilo. Tiene una iglesia sencilla, erigida por los frailes dominicos, en cuyo interior hay un retablo de gran valor artístico, esculpido en madera y adornado con algunas pinturas buenas, que, por desgracia, están sumamente descuidadas y maltratadas. Al pie del retablo, en ambos lados, hay una inscripción que reza como sigue:

TALLOSE, I DO-

ROSE ESTE RE-

TABLO A COSTA

DEL SENOR

MAESTRE DE CAMP.

PO.
DON SEBASTIAN

DE OLIVERA PON-

SE DE LEON, I DE

LA Sa. Da. ANA DE

AGUILAR SU MVGER.

Cuando se trata de datos históricos de los tiempos virreinales siempre acudo a la sabiduría de mi fino amigo Monseñor Eduardo Flores y él, siempre amable, me facilitó los datos siguientes sobre el interesante retablo de Teopisca:

El Maestre de Campo, don Sebastián de Olivares Ponce de León era español y estuvo en San Cristóbal las Casas a principios del siglo xvrrn. Murió allí por el año de 1714. Era dueño de la casa situada en la esquina de la Plaza Mayor, frente al Seminario Conciliar, ahora derribada por Hernán Pedrero con la mira de construir un hotel moderno. Legó sus bienes al Colegio de la Compañía de Jesús. Se cree que el retablo que ahora se conserva en el pueblo de Teopisca, fué construído en vida del mismo, ya que vivía entonces su mujer y al morir no habría legado sus bienes a una institución de haber tenido herederos forzosos.

2 Ximénex, Fr. Francisco. Historia de la Provincia de San Vicente de Chiapas y Guatemala. Edición Biblioteca Guatemala. I-IIt,

3 Orozco y Jiménez, Francisco. Obispo. Colección de documentos inéditos relativos a la iglesia de Chiapas. I-II. 


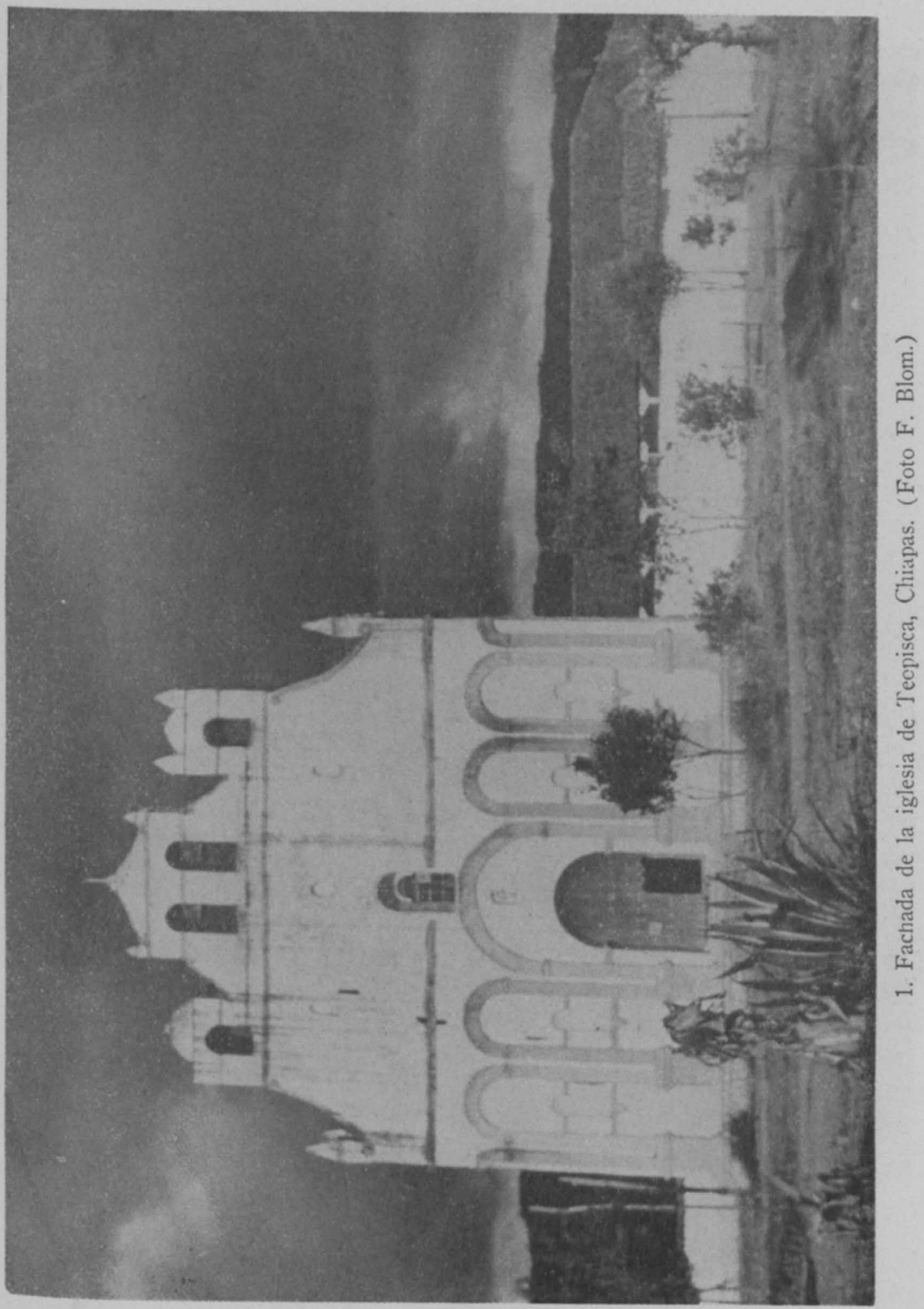




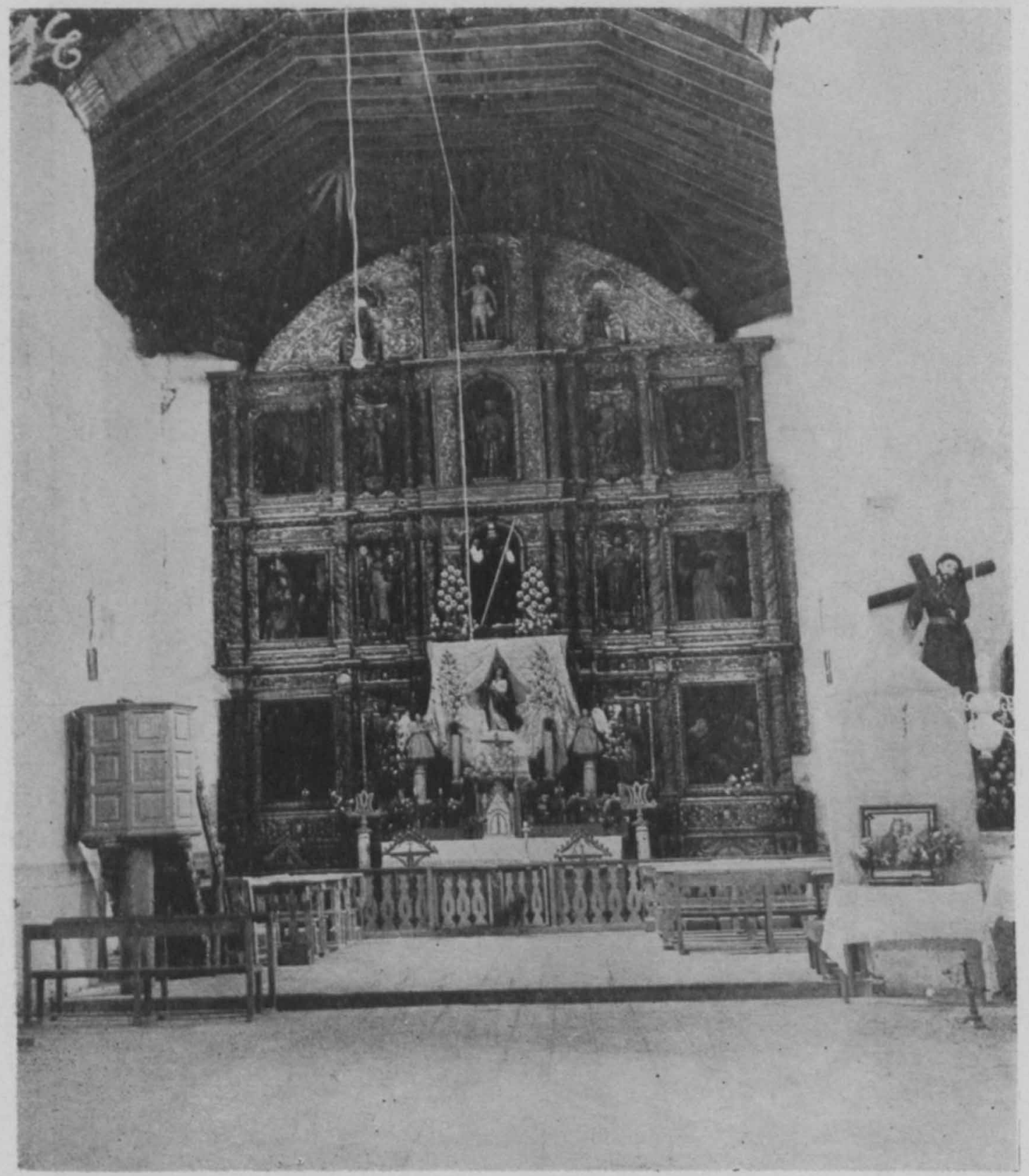

2. Retablo de la iglesia de Teopisca, Chiapas. (Foto F. Blom.) 


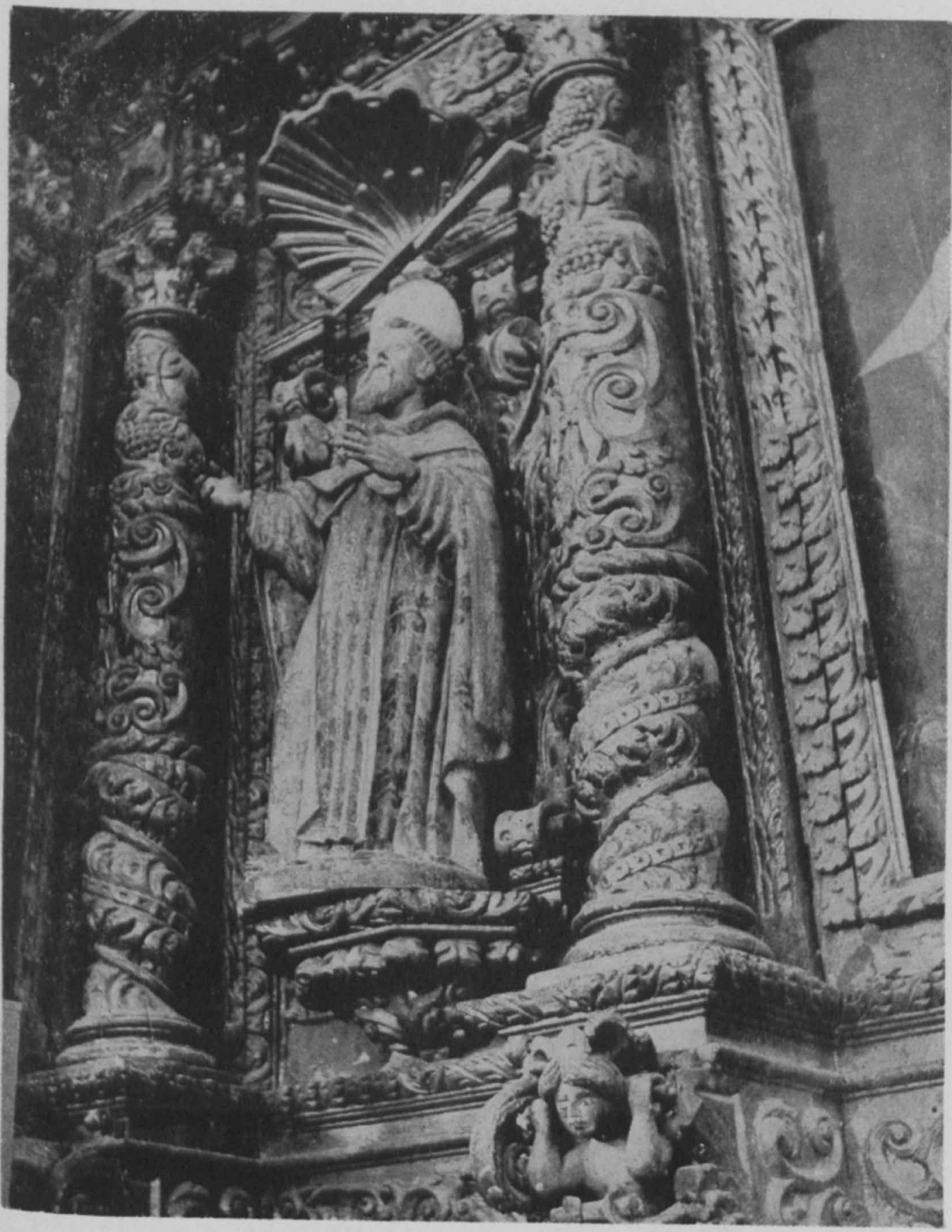

3. Detalle del retablo. Teopisca. Chiapas. (Foto F. Blom.) 


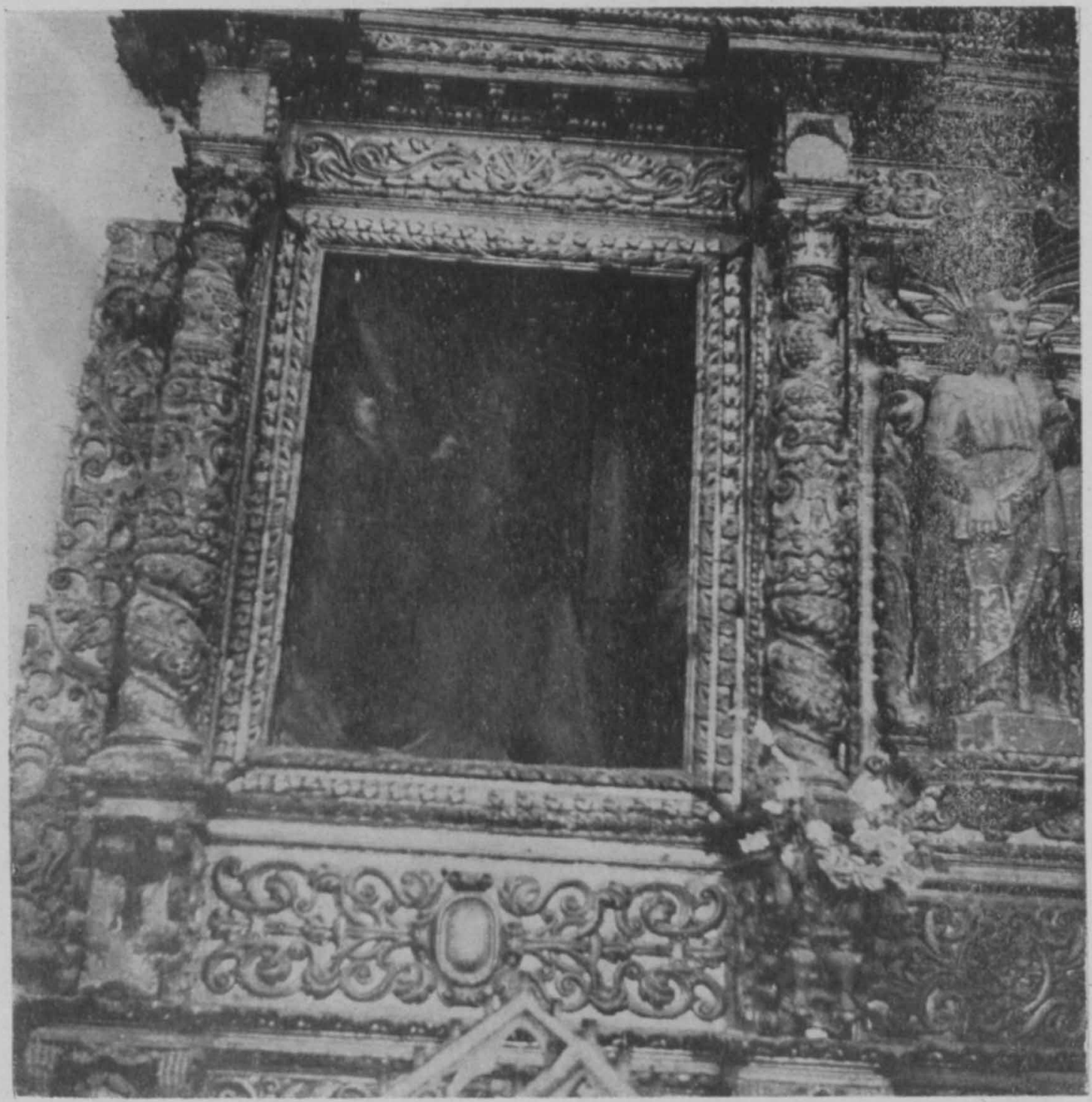

4. Detalle del retablo. Teopisca, Chiapas. (Foto F. Blom.) 


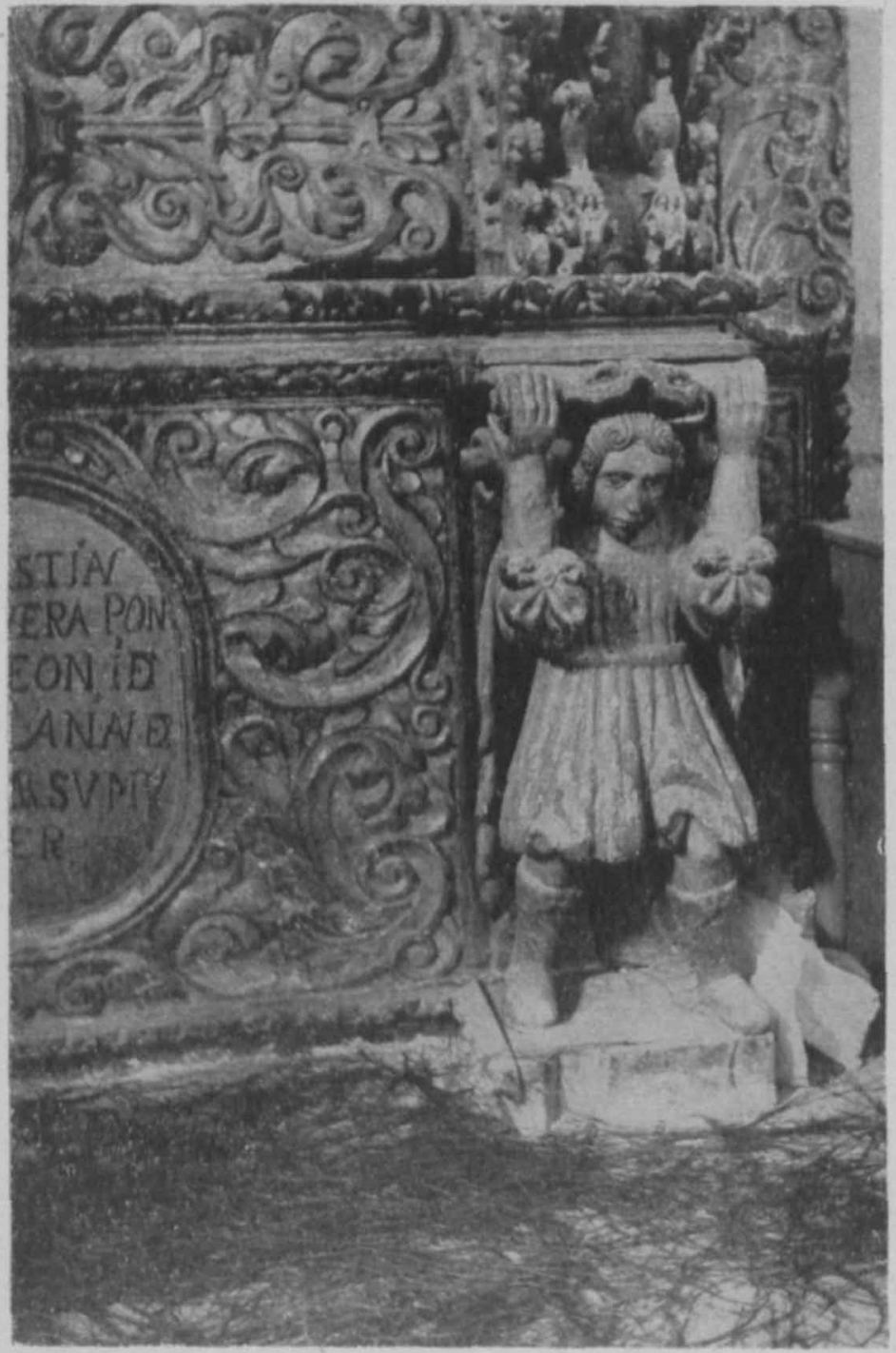

5. Detalle del retablo. Teopisca, Chiapas. (Foto F. Blom.) 


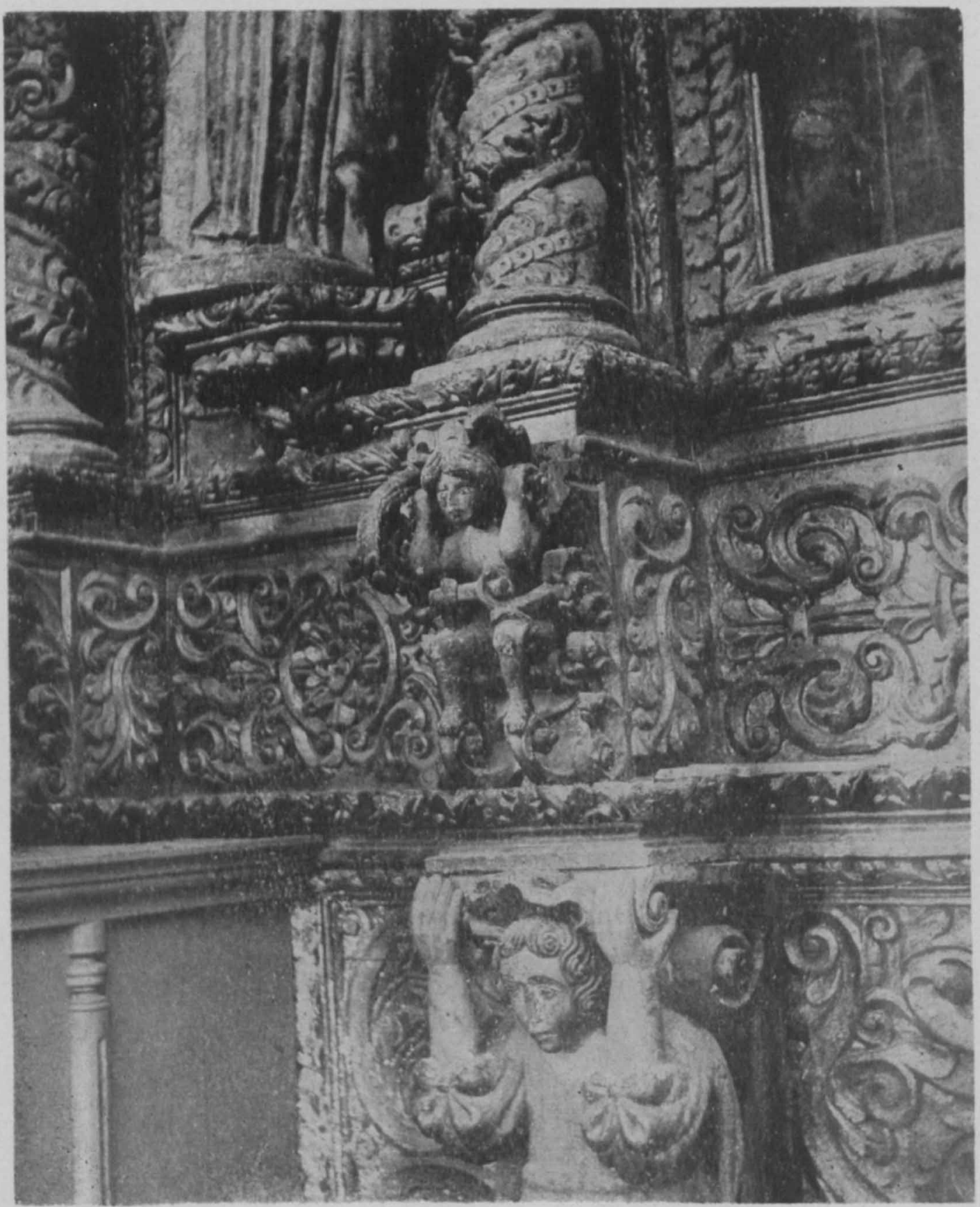

6. Detalle del retablo. Teopisca, Chiapas. (Foto F. Blom.) 
Queda por tanto confirmado lo de que el retablo en cuestión perteneció a la iglesia de San Agustín en esta ciudad, de donde fué llevado a Teopisca de orden del obispo don Ramón Moreno y Castañeda el año de 1881 poco más o menos.

Puesto que el Colegio de la Compañia se fundó a fines del siglo xvir, el retablo debe ser muy poco posterior y, ciertamente, anterior a 1714, cuando los donantes existían, de acuerdo con la inscripción.

Los datos insertos están tomados de un documento original, en donde consta que su albacea, don Antonio de Valtierra Rivas, jesuíta, fundaba por mandato del difunto, una capellanía en 9 de octubre de 1714 .

La iglesia de San Agustín de San Cristóbal las Casas está ahora completamente abandonada y vacía por dentro. Sólo fragmentos de un marco de madera profusamente tallado, cuelga, ya para caerse, sobre una puertecita en el lado norte del interior. Da pena ver el poco respeto que tiene el pueblo Sancristobalense a su patrimonio histórico y a las tradiciones de su pasado glorioso.

"Hay que hacer notar que las esculturas son de diferentes tamaños, siendo las más altas las del primer cuerpo y las más pequeñas las del remate. Esto puede observarse en muchos retablos y fachadas en los que decrecen las dimensiones de los cuerpos horizontales y es un principio para saber si han sido removidas las esculturas de sus primitivos lugares. El San Pedro del primer cuerpo es la imagen de mayor altura, y así debió ser la de su necesario compañero San Pablo. ¿ No será éste el que está en el tablero central, arriba de la Virgen, vestido con telas modernas? El lugar que debió ocupar lo llena hoy una escultura al parecer de un mercedario (¿San Raimundo, el fundador de la Orden de la Merced?) que sin duda debió ir arriba.

En el segundo cuerpo están Santo Domingo y San Francisco y en el tercero, en medio, San Ignacio, y a los lados, según parece, otros fundadores de órdenes de la Contrarreforma, con sotana y sin hábito especial (¿ San Felipe Neri? ¿San Camilo?).

En el remate, en el centro, un San Sebastián y a los lados dos santos jóvenes, mujer la de la izquierda y varón a la derecha.

A juzgar por los rostros, actitudes, vestidos y expresiones son todas las esculturas de una misma mano o de una sola dirección, salvo 
el San Sebastián que se distingue de manera absoluta; parece mucho más antiguo (o más imperfecto) por lo sobrio y hierático.

Lleva tres órdenes de columnas. En el primer cuerpo salomónico, pero divididos sus tercios en forma inusitada: Helicoidal el primero con cenefas ornamentales; el segundo no se segmenta a la manera salomónica y se adorna con roleos, y el tercero vuelve a la forma helicoidal y se decora con racimos de uvas. En el segundo cuerpo si son plenamente salomónicas, con ornamentación vegetal $y$ en el tercero son columnas rectas, ornamentadas con lazos geométricos en forma de rombos dentro de los cuales van hojas estilizadas. El remate se decora con enormes hojas de acanto." (Nota añadida con permiso del autor por Francisco de la Maza.) 